\title{
HEALTH SERVICES OF NORTHERN IRELAND
}

\author{
BY \\ A. T. ELDER \\ From the Ministry of Health and Local Government, Stormont, Belfast.
}

\section{(1) Central Organization}

The modern health service of Northern Ireland began on July 5,1948 , in common with that in Great Britain. It is based on the Health Services Act (Northern Ireland), 1948, the provision of which was part of a programme of social legislation passed in Northern Ireland to keep pace with similar laws in England:

Health Services Act (Northern Ireland), 1948

National Assistance Act (Northern Ireland), 1948

National Insurance Act (Northern Ireland), 1946

National Insurance (Industrial Injuries) Act (Northern Ireland), 1946

Disabled Persons (Employment) Act (Northern Ireland), 1945.

Centrally several branches operate on much the same lines as in the British Service. These include the National Insurance and Factory Medical Services under the control of the Ministry of Labour and National Insurance, the Medical Referee Service controlled by the Ministry of Health and Local Government, the care of deprived children operated by the Ministry of Home Affairs (cf. Home Office in London), and a Registrar-General's Department for medical and vital statistics. In general, Northern Ireland has allowed a large measure of devolution of responsibility for the health services. Thus, while the Government exercises a general supervision, the day-to-day operation of the services is controlled by various statutory bodies, such as the Northern Ireland Hospitals Authority, the Northern Ireland Tuberculosis . Authority, the Northern Ireland General Health Services Board for general practitioner services, the Health and Welfare Authorities, and the Housing Trust.

It is important to note that ownership of hospitals lies with the appropriate authority, a fundamental difference from the legal practice in England (Ormrod and Walker, 1950). Furthermore, the hospitals authority was charged not only with the provision of new hospitals but also with the provision of facilities for medical and dental research. Such facilities can be given to any body or persons, so that while, by the School Health Service Regulation (Northern Ireland), 1948, the Health Authorities in Northern Ireland may prosecute research, grants for this purpose are obtained from the appropriate committee of the Hospitals Authority. The Ministry of Health and Local Government in Northern Ireland has no legal right to originate or prosecute research as has the Ministry of Health in England (Ormrod and Walker, 1950). On the other hand, the Ministry's power in Northern Ireland is limited to the duty of ensuring adequate co-ordination of services within the powers laid down in the various health enactments.

It may be asked whether such a scheme of devolution of ownership and responsibility is satisfactory. Much depends upon the interpretation by the Central and Local (Hospital) Authorities of their individual responsibilities. For instance, though it is a duty of the Local Authority to provide hospitals, it is also the implied duty of the central authorities to ensure that:

(a) minimum technical and professional standards are maintained in new buildings and extensions;

(b) no excessive or extravagant spending of public money is incurred;

(c) the medical and social needs of each area are met.

Within the framework of such obligations the authority is free to develop its own resources.

The Ministry of Health and Local Government acts as a medium of final appeal in any difficulties and disputes referred to it by the Local Authority.

It would be inaccurate to say that the Hospital Services had developed without difficulties, yet the administrative organization has been built up by the authority with considerable efficiency, and the over-riding power of the Ministry has been exercised only to a very small degree. Indeed, the authority has borne the full brunt of all the initial difficulties attendant upon the establishment of a new service out of the diverse components mentioned below.

The provision of health centres is, by law, a matter for the General Health Services Board and not one for Health Authorities. This gives the Board a wider field of activity and better status than the Executive Councils have in England, but so far no health centres have been set up. 
Suggestions for group practice are now being considered by the Board under new regulations comparable to those issued in Great Britain.*

The absence of health centres has not prevented the establishment of local health authority multipurpose clinics.

It was incumbent on the Province to proceed with the establishment of an effective Public Health Service under the Public Health and Local Government (Miscellaneous Provisions) Act (Northern Ireland), 1946, and the provision of ante-natal, post-natal, school and child welfare clinics has followed a policy dictated by circumstances.

\section{(2) The Hospitals Authority}

The hospitals of the Province originated in the following diverse systems:

(a) The voluntary teaching group in Belfast from an early Belfast General Hospital, as a result of a Dispensary Act of 1817.

(b) A so-called voluntary group of county hospitals built after a County Infirmaries Act of 1765 .

(c) The workhouse system, entirely rate-aided and dating from the 1840 s, including most of the fever hospitals.

(d) Voluntary cottage hospitals dating from the late nineteenth century.

(e) County mental hospitals originating about 1828 .

(f) Chest hospitals built as County and County Borough sanatoria (apart from one or two private ones).

(g) A war-time emergency hospital in Belfast (from the Second World War).

(h) A few minor additions by way of country mansions converted during the post-war era.

Several surveys of the needs of the Province have been made from time to time, the most notable being the Nuffield Regional Hospitals Council Survey (Red Book, 1946). Thus the material available and the ultimate requirements of the Province were well enough known by July 5, 1948 .

The lag in hospital development stressed by the Nuffield Surveyors has meant the acceptance of a heavy capital building programme in order to .bring hospital provision in line with that in Great Britain. Thus in 19093,500 beds were available for clinical instruction in Belfast, and 10,000 in the Province as a whole. By 1952 there were 14,100 beds, and the building programme envisages an increase to over 17,700 by 1962 , made up of approximate increases in the following categories :

$\begin{array}{lllllr}\text { Geriatrics } & \ldots & \ldots & \ldots & \ldots & 1,000 \\ \text { Mental . } & \ldots & \ldots & \ldots & \ldots & 600 \\ \text { General Medical } & & \ldots & \ldots & \ldots & 300 \\ \text { General Surgical } & \ldots & . & \ldots & 400 \\ \text { Maternity and Gynaecological } & & & \ldots & 200\end{array}$

*Health Services (General Medical and Pharmaceutical Services) (Amendment No. 2) Regulations (Northern Ireland) 1953.

$$
\begin{aligned}
& \begin{array}{llllll}
\text { Paediatric } . . & \text {.. } & \text {. } & \text {.. } & \text {.. } & 200
\end{array}
\end{aligned}
$$

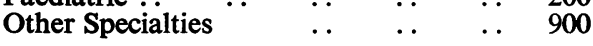

$$
\begin{aligned}
& \text { Total } \ldots . \quad \ldots \quad 3,600
\end{aligned}
$$

This programme includes three or four new general hospitals and a colony for persons requiring special care on account of mental deficiency, but excludes tuberculosis provision, which is to be dealt with separately.

This new provision is spread over a period of time for financial reasons, and is conceived for the whole field of the needs of the various Management Areas. New specialized units, such as a Radiotherapy Centre and a Plastic Surgery Unit, have been established, and, in general, it may be stated that except at the Royal Victoria Hospital Teaching Unit in Belfast City, waiting lists are nowhere very large.

From an economic viewpoint, the proposed new special beds are well within the limits advised for England by the Ministry of Health (1950), and with the full development of Health and Welfare Services some of this new building may prove to be unnecessary. Nevertheless as a result of the lag in building, there is at present still some difficulty in housing the aged and the mentally sick.

The hospitals, numbering just over 70 , are grouped under 23 Hospital Management Committees. The teaching hospitals are not separated from the others as in England, though they are managed by aco separate Management Committee. The mental? hospitals, while nominally under the Hospitals Authority, are managed by a Mental Health Services Standing Committee; those tuberculosis hospitals which are concerned wholly with the treatment of tuberculosis are vested in the Northern Ireland Tuberculosis Authority, but where a tuberculosis wing exists in a general hospital, the responsibility of maintenance lies with the Hospitals Authority, access for treatment being afforded to the medical staff of the Tuberculosis Authority. The Hospitals Authority is also responsible for the provision of the Ambulance Service.

A few anomalies may be noted. One large Roman Catholic teaching hospital elected to remain outside the Health Service Scheme, and exists quite independently to-day as a voluntary institution. Two hospitals dealing with ex-Service patients remain, as before, associated with the Ministry of Pensions (London) and independent of the Northern Ireland Hospitals Authority. One tuberculosis sanatorium, previously a voluntary institution, elected not to be absorbed into the Tuberculosis Authority organization set up under the Public Health (Tuberculosis) Act (Northern Ireland), 1946, but was later absorbed 
by the Hospitals Authority, and is now part of the latter service though it still deals only with tuberculous patients.

The Mental Treatment Act (Northern Ireland), 1932, was embodied into the Mental Health Act (Northern Ireland), 1946, together with something equivalent to the English 1913 Mental Deficiency Act and the functions of the Mental Health Services include provision for the prevention, diagnosis, and treatment of mental illness and co-operation with other public bodies. A Special Care Management Committee deals with the day-to-day work at institutions for "persons requiring special care", a terminology introduced in order to remove the stigmata of expressions such as "idiot", "imbecile", etc. Certain amendments were introduced in 1953 by a new Act but these were largely of a domestic nature and the fundamental basis of certification and care remains unaltered. Certification of children over 2 years of age is dealt with below under the work of the Health Authorities.

\section{(3) General Practitioner Services}

The Northern Ireland General Health Services Board, established by the Health Services Act (Northern Ireland), 1948, consists of a chairman, vice-chairman, and 23 members, and includes representatives from the medical, dental, and pharmaceutical professions, the Health Authorities, and other organizations which appear to be concerned. The staff includes a medical adviser and a lay secretary. At its inception there were approximately 750 general practitioners in the Province, and with few exceptions they contracted with the Board to provide general medical services to the public.

Conditions of service and benefits to the public follow closely and speedily the appropriate changes which have come about in Great Britain. Payments to practitioners, as in England and Wales, include basic capitation fees, "loadings", and special fees allowed by the 1953 Regulations. In view of reports that the Province was over-supplied with doctors, restriction of entry into general practice was sought by the terms of the Temporary Provisions Act (Northern Ireland), 1950. This Act has had the effect of closing the Medical List but the Board is able to admit practitioners where necessary.

As in Great Britain, the general practitioner is anxious to have access to hospital work, but in Northern Ireland this has been limited to eight hospitals of the cottage hospital type, and a few others, mainly for midwifery. With the development of the general hospitals, specialized units, and resident establishments, it is difficult to see how access can be much increased at present.

General practitioners may contract with the Health Authorities for the provision of domiciliary midwifery services, under the auspices of the Ministerial Maternity Services Advisory. Committee. This service has functioned smoothly since its inception; special qualifications and experience are not required from practitioners taking part in it, though refresher courses in midwifery are organized by the Medical Services Board from time to time.

Before 1948, there were not enough dentists in the Province to provide an adequate service. Although the position is now somewhat improved, and the introduction of charges has reduced the adult demand, it may be some years before these difficulties are overcome. Surprisingly, this does not apply to the Local Health Authority services, whose dental establishments are now complete.

\section{(4) Health and Welfare Authorities}

These Authorities, consisting of one Health and one Welfare Authority for each County and County Borough, acting through the medium of statutory committees, were brought into being by the Public Health (Administrative Provisions) Act (Northern Ireland), 1946. Two interesting features of the operation of the Act are:

(a) The transfer of the responsibility for School Health Services from the Education Committees to the Health Committees, so that the medical officer of health is automatically also chief school medical officer for his area and his staff is responsible for personal school health services. Control of expenditure on new buildings, and the provision of special schools, together with the operation of the school meals and milk scheme remains with the Education Committees and the corresponding Ministry.

(b) Whereas in England the medical aspects of the Domiciliary Maternity Service are vested in the Executive Councils, these functions are performed in Northern Ireland by the Health Committees.

Ascertainment of handicapped children is a matter for the Health Committees, except that children over 2 years of age suffering from mental retardation of such a nature as to render them incapable of education in a special class or school are notified to the Hospitals Authority, and they then come under the care of the Mental Health Services Committee.

The details of the integration of the preventive services have been discussed by Elder (1950), but a few words may be said here regarding the general policy adopted for public health. The provisions of the Health Services Act (Northern Ireland), 1948, which apply to the duties and permissive functions 
of Health Authorities in Northern Ireland followed exactly the pattern laid down for similar authorities in England and Wales by the National Health Service Act, 1946, with the exception of the domiciliary midwifery medical services outlined above. As these authorities-were newly formed when the General Health Service was started it was considered politic to ask from each authority interim proposals only for the first 5 years. In 1953, comprehensive proposals were called for to cover the ensuing 5 years, and these deal amongst other matters with the fully developed schemes of clinical services and permissive functions, such as after-care arrangements.

The Health Authority Services now carry their full establishments of medical officers, midwives, and home nurses, almost a full establishment of health visitors and sanitary officers, and a full complement of dentists (except orthodontists).

The Health Authorities planned for their own purposes solely, and proposals for additional clinics follow the usual pattern of:

(a) Multi-purpose clinics in populous areas;

(b) Smaller child-welfare clinics in rented premises in less populous areas;

(c) Mobile clinics in sparsely populated districts.

Special arrangements are to be made for the development of speech therapy, child guidance, and ophthalmic and physiotherapy sessions, while the development of consulting obstetric facilities on general practitioner/midwife ante-natal sessions appears to find favour.

Registers of physically handicapped children are maintained, but building difficulties have caused some delay in the provision of an adequate number of special schools for the physically handicapped.

The transfer of Welfare Services from pre-existing Boards of Guardians to new Welfare Authorities analogous to the Health Authorities was a necessary part of the new scheme. The abolition of the Poor Law, envisaged in the Administrative Provisions Act of 1946, was completed by the passing of a Welfare Services Act in 1949, by which the care of handicapped persons was vested in the Welfare Committees, the system adopted including the giving of financial aid to existing voluntary agencies.

Legislation dealing with the care of "deprived" children, and the protection of children generally, has closely followed the pattern developed in England, though it appears that the link with the medical officer of health in preventive health matters is not as strong as it might be.

\section{(5) Tuberculosis Authority}

In 1946, when the Tuberculosis Authority was formed, the death rate from all forms of tuberculosis in Northern Ireland was 83 per 100,000 of population, against 79 for Scotland, 115 for the Irish Republic, and 55 for England and Wales. Although the death rate had fallen progressively from 166 in 1922 it was still so high as to be considered a matter of grave moment. The Authority was formed because of the need for a public body to act as a spearhead of attack. It mainly comprised representatives of the local government preventive services. It has altered its complexion and now includes a highly organized clinical service. The officers at first included a lay secretary and a medical director, but after the adoption of the Spens Report on Medical Salaries some internal re-organization took place, as a result of which there are now a number of chest consultants but no director. The reports of the Authority should be studied with this radical change in mind, remembering also that the Authority is by law charged with the duty of preventing as well as that of curing the disease.

There were certain initial weaknesses in the pattern of tuberculosis control. The liaison with the medical officers of health is now very much closer, copies of all notifications being sent to the appropriate M.O.H., and use being made on an agency basis of certain officers of the Health Authorities, such as home nurses, to avoid duplication.

The questions which would naturally be asked would no doubt include the following:

Is the preventive aspect of the work of the Authority receiving sufficient attention?

Does the absence of a medical man specifically charged with the duty of assessing the medical statistics lessen the effectiveness of control?

Have the Authority and the Health Authorities of Counties and County Boroughs achieved a sufficient degree of co-operation?

The total number of definite new cases notified during 1951 was 2,063 (1,751 pulmonary and 312 non-pulmonary):

The decline in the number of cases notified, which was observed last year, has continued (1,848 in 1952), and, whilst it is probably too soon to say that there is anything significant in these figures, the downward trend is nevertheless encouraging.

The death rate for 1952 was 30 per 100,000 of population, having fallen from 45 in 1951. This compares with 31 for Scotland and 32 for England and Wales. The Tuberculosis Act had introduced also a system of "intimation of suspected tuberculosis", which had led to an increase in dispensary examinations from a pre-war annual figure of 5,000 to 40,000 . 
The Mass Miniature Radiography Service has become exceedingly active and in 1952 more than 75,000 people were screened. The trend noted in the annual reports is that of progressive and adequate provision of equipment, clinic facilities, and radiography services; the waiting list for admission to chest hospitals has been reduced from 700-800 5 years ago to just over 200 in 1952. Admittedly some overhaul of the waiting list had been necessary in any case, but prima facie we are presented with a substantial reduction.

B.C.G. vaccinations had totalled 6,000 by 1951 , but statistics are incomplete. The following statement appears in the Report for 1952:

The Authority realizes that if B.C.G. is to be widely applied within a relatively short space of time, the active support and co-operation of the Northern Ireland Hospitals Authority, and the County and County Borough Health Committees must be secured, and arrangements are about to be made to discuss with these bodies the best ways and means of carrying the scheme into maternity hospitals, schools, and child welfare clinics.

That support has been given and a province-wide scheme of vaccination of school leavers has been started. During the third quarter of 1952 the Registrar-General in Northern Ireland reported a mortality rate of 20 per 100,000 of population, a fact which augurs well for the future.

If that portion of the cost of tuberculosis control which can be directly accredited to preventive measures is added to the total cost of local government public health services, the quantum of national expenditure on prevention in Northern Ireland is slightly less than that in England and Wales. It is too soon to say definitely whether a Tuberculosis Authority as such has achieved what energetic measures equally applied along the lines of the system in Great Britain could not have achieved.

\section{(6) Other Services}

(a) Factory Medical Service.-This is administered by the Ministry of Labour and National Insurance, but medical inspection is carried out by the physicians of the Ministry of Health and Local Government. The question of what form an industrial health service should take is fraught with much difference of opinion, and the theoretical considerations are too well known to require any elaboration here. In Northern Ireland we have the economic reality that the cost of the present service is met by industry itself, and it has to be admitted that very little in the way of real industrial hazards as yet exist in the Province (Hamilton, 1951). Moreover, the general practitioners appointed have been doing the work of examination of entrants into industry for some considerable time. The Factory Acts of Northern Ireland are almost complete facsimiles of the English Acts.

(b) Laboratory Service and Control of INFeCTIOUS DisEASES.-Before the inception of the Health Service, apart from the teaching school, the Belfast City Laboratory, and one or two smaller hospital laboratories, little existed by way of a public health laboratory service. Interim developments during and immediately after the Second World War led to the opening in 1953 of a new three-storeyed central public health laboratory in Belfast. A chain of subsidiary laboratories throughout the Province will work with the central reference laboratory. Meanwhile a series of collecting depots has been established where practitioners can leave specimens daily for collection and transportation to Belfast.

\section{(7) Financial Considerations}

The comparison of general costs in Northern Ireland with facts given in the excellent summary of Ross (1952) shows that the running costs of the hospital service are, if anything, a little less than those in Great Britain; and the costs of the preventive health services are lower by more than one-fifth. The proportionate running costs of the preventive health services amount to about one-eighth of the total health services expenditure. Though theadministrative pattern of the tuberculosis services is different, it is possible to separate out costs appropriate to preventive measures and thus arrive at a reasonably true comparison with proportionate costs in England and Wales.

It must be admitted that these facts take no account of the capital investment programme necessary to bring hospital provision in Northern Ireland into line with provision in Great Britain per unit of population. This will cost the Province at least $£ 14$ million. Nor has any money yet been spent on the erection of multi-purpose health centres such as those at Woodbury Down or Edinburgh.

The cost of prescribing in Northern Ireland was admittedly excessive at the outset, but by 1953 the excessive cost had been halved. This statement is based on a comparison with Great Britain and should not be misread as a halving of the total cost, an ideal as yet somewhat remote.

Finally, in spite of all efforts to control expenditure, the Ministry of Health and Local Government Budget for 1953-54 shows an increase of $£ 378,210$ over the corresponding provision for last year to a total of $£ 19,752,290$, which includes an increase of 12 per cent. to the Hospitals Authority. 
TABLE I

HEALTH AND WELFARE SERVICES ESTIMATES

\begin{tabular}{|c|c|c|c|}
\hline Year & .. & $1953-54$ & $1952-53$ \\
\hline Statutory & $\begin{array}{l}\text { A.-Grants to Welfare Autho- } \\
\text { rities under the Welfare } \\
\text { Services Act (N.I.), 1949 .. } \\
\text { B. School Health Services } \\
\text { under the Education Act } \\
\text { (N.I.), 1947.. } \quad . .\end{array}$ & $\begin{array}{c}£ \\
40,700 \\
165,000\end{array}$ & $\begin{array}{c}f \\
40,000 \\
161,000\end{array}$ \\
\hline $\begin{array}{c}\text { Extra- } \\
\text { statutory }\end{array}$ & $\begin{array}{l}\text { C.-Health Education Grants } \\
\text { D.-Grants for Nurses train- } \\
\text { ing as Health Visitors } \\
\text { E.-Welfare Foods } \\
\text { F.-Remanet of N.I. Evacua- } \\
\text { tion Service } \\
\text { G.-Grants in Aid to the N.I. } \\
\text { Council of Social Service.. } \\
\text { Nurses' Salaries Grants }\end{array}$ & $\begin{array}{r}50 \\
10 \\
115,000 \\
100 \\
3,000\end{array}$ & $\begin{array}{r}50 \\
375 \\
107,000 \\
6,110 \\
3,000 \\
65\end{array}$ \\
\hline & . & $£ 323,860$ & $£ 317,600$ \\
\hline
\end{tabular}

The total estimate for all services under the Government of Northern Ireland for 1953-54 is $£ 52,728,680$, but in making comparisons with Great Britain it must be remembered that the lists of items of the domestic budget of the Province is different from that of the United Kingdom as a whole, which also includes the medical services of the Post Office, and Armed Forces, and so on. Again the Ministry of Health and Local Government deals not only with Health Services but with Housing and Local Government matters. Finance is therefore more appropriately related to population $(1.4$ million). Tables I and II give the comparative estimated expenditure for the years 1952-53 and 1953-54.

It should be mentioned also that Local Health Authority Services are subject to a 50 per cent. Government Grant (this includes the Domiciliary Maternity Service), the General Health Services to a 100 per cent. grant, and the Tuberculosis Services to a 100 per cent. grant, except those that can be classified as Welfare Services.

\section{(8) Co-ORDination}

Northern Ireland, with a population of approximately 1.4 millions, about one-third of which is aggregated in the City of Belfast, comprises one compact region of 5,238 square miles. The operation of the services by centralized authorities acting independently of, but co-ordinated by, the government departments is assisted by geographic and social requirements.

In the general field of co-ordination, a useful innovation was the establishment of a liaison committee consisting of the Tuberculosis Authority, Health Authorities, Hospitals Authority, and

TABLE II

SUMMARIZED EXPENDITURE FOR ALL HEALTH SERVICE (ESTIMATES)

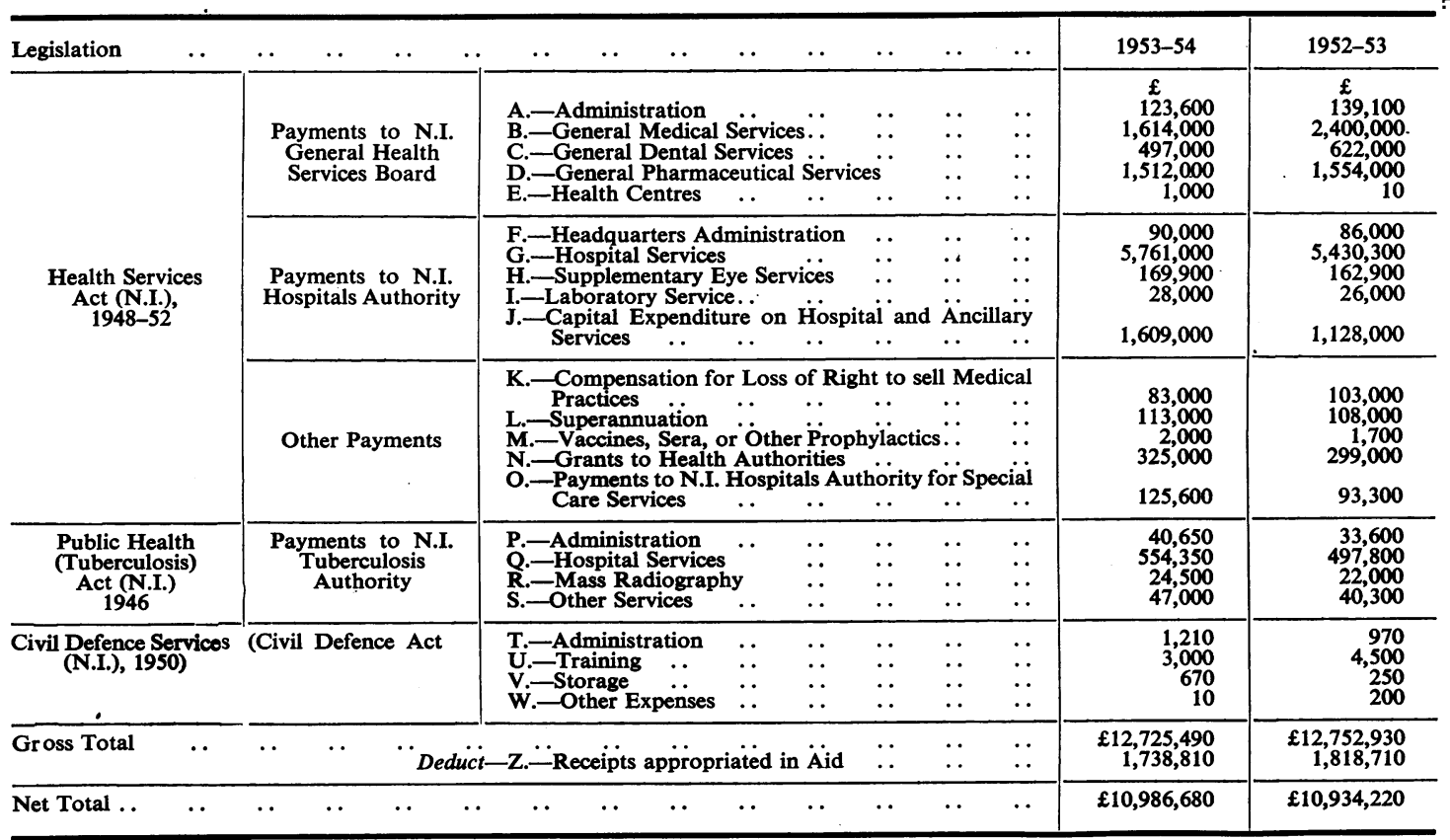


General Health Services Board. There are as yet no University members or Ministry observers.

After-care services have not yet had time to become fully organized, and it is hoped that the full development of home nursing and after-care now envisaged in the Health Authorities' final comprehensive proposals will have the effect of reducing hospital and building costs by speeding up the turnover of beds and reducing the need for in-patient provision.

The co-operation of the Health Authorities in the B.C.G. vaccination service is a welcome development. Ophthalmic, orthopaedic, and child guidance clinics should provide close links between health, education, and hospital committees.

The Ministry of Health and Local Government is given wide powers of co-ordination under the Welfare Service and Health Service Acts.

Under the new Health Services Act (Northern Ireland), 1953, the Minister is given new powers to require from the statutory bodies proof of due performance of certain functions under the Health Services and Tuberculosis Acts.

The benefits of the Health Service are made available to citizens of the United Kingdom generally, and can be made available to other non-residents subject to such exceptions as may be described, "in accordance with a scale of charges" approved by the Ministry.

As far as officers employed in the General Service are concerned, reciprocity of superannuation exists for those in the General Health Services and also for Local Government officers under the Local Government Superannuation Act (Northern Ireland), 1950.

Slight differences of administration exist, but, these apart, it could truly be said that any resident of great Britain coming to live in Northern Ireland would notice very little difference in the availability of services.

\section{SUMMARY}

A very brief description has been attempted of the Medical Services of Northern Ireland, with special reference to differences between them and similar services in Great Britain.

\section{REFERENCES}

Beveridge, W. (1942). "Social Insurance and Allied Services", H.M.S.O., London.

Elder, A. T. (1950). J. roy. Soc. Med., 43, 29.

Hamilton, J. (1951). "Report of Chief Lespector of Factories for Northern Ireland"; H.S. B. Belfast.

Ministry of Health (1950). "National Health Service: Development of Consultant Services". H.M.S.O., London.

Government of Northern Ireland: Ministry of Health and Local Government (1951): Departmental Report. H.M.S.O., Belfast.

Northern Ireland. Tuberculosis Authority (1947-51): First to Sixth Annual Reports (1946-50).

Nuffield Regional Hospitals Councils Survey: Red Book (1946). Northern Ireland Regional Hospitals Council, Provincial Bank

House, Belfast.
Ormrod, R., and Walker, H. (1950). "The National Health Service". Butterworth, London. (Reprinted from Butterworth's Annotated Legislation Service.)

Roberts, F. (1952). "The Cost of Health". Turnstile Press, London. Ross, J. Stirling (1952). "The National Health Service in Great Britain", p. 384. Oxford University Press, London. 